\title{
CULTURA POPULAR NOS ARQUIVOS DE MÁRIO DE ANDRADE: NA PANCADA DO GANZÁ E OS FUNDOS VILLA-LOBOS
}

Beatriz Lopes ${ }^{1}$

André Luís Gomes ${ }^{2}$

\section{RESUMO}

Consciente de que vivia em um mundo cada vez mais direcionado para a desaparição das autenticidades culturais, Mário de Andrade almejava levar a termo um projeto de preservação da "autenticidade" da cultura brasileira, por isso ele planeja, esboça, organiza suas recolhas e estudos, e inicia as escrituras de sua "grandiosa" obra, Na pancada do Ganzá. Para os objetivos deste artigo, que apenas se propõe a apontar as possibilidades de um novo diálogo cultural entre Mário de Andrade, artistas e músicos populares, inclusive Pixinguinha, apresentamos uma pequena síntese do que se anuncia na pesquisa de arquivos e obras que referendam o projeto do musicólogo Na pancada do Ganzá e os Fundos VillaLobos, acervo poético-musical nele inseridos.

Palavras-chave: Mário de Andrade. Na pancada do Ganzá. Os Fundos Villa-Lobos. Dialogismo. Cultura popular.

\section{POPULAR CULTURE IN MARIO DE ANDRADE'S ARCHIVES: "NA PANCADA DO GANZÁ" and "OS FUNDOS VILLA-LOBOS"}

\section{ABSTRACT}

Aware that he lived in a world increasingly directed to the disappearance of cultural authenticity, Mário de Andrade longed for taking forward a project to preserve the "authenticity" of Brazilian culture, so he plans, outlines, organizes their collections and studies, and initiates the scriptures of his "great" work, Na pancada do Ganzá. 
For the purposes of this article, that it is proposed to indicate the possibilities of a new cultural dialogue between Mário de Andrade, artists and popular musicians, including Pixinguinha, we present a short summary of what was advertised on archival research and works that endorse the musicologist's project, Na pancada do Ganzá and Fundos Villa- Lobos collection poetic-musical contained therein.

Key-words: Mário de Andrade. Na pancada do Ganzá. Fundos Villa-Lobos. Dialogism. Popular culture.

Do fundo das imperfeições de tudo quanto o povo faz, vem uma força, uma necessidade que, em arte, equivale ao que é a fé em religião. Isso é que pode mudar o pouso das montanhas. Mário de Andrade, Na pancada do Ganzá, Prefácio.MA-MMA-074IEB/USP).

\section{CULTURA POPULAR NOS ARQUIVOS DE NA PANCADA DO GANZÁ}

No âmbito da literatura brasileira, Mário de Andrade é um autor cujas obras apresentam uma complexidade formal amplamente reconhecida. $\mathrm{Na}$ abordagem de Macunaíma, por exemplo, tal complexidade leva geralmente à sondagem das fontes básicas de nossa cultura: a Europa (as vanguardas europeias) e as culturas indígenas e negro-africanas (explicação mítica), fundando-se na tradição e na oralidade para construir sua obra. Desse modo, o escritor brasileiro estabelece uma relação entre a obra de arte e a cultura, criando assim uma nova forma de narrativa calcada na experiência cultural e não apenas na experiência social. E essa imersão profunda na cultura brasileira, especialmente em suas raízes e diversidades de manifestações populares, para compreendê-la e melhor amá-la, como bem o expressa no Prefácio ${ }^{3}$ da obra em preparo Na pancada do Ganzá, tornou-se para o estudioso mais que um compromisso de vida: uma paixão:

[...] não pretendi fazer obra de etnógrafo, nem mesmo de folclorista, que isso não sou: pretendi foi assuntar, atocaiar com mais garantias a namorada chegando. Se acaso algumas constâncias me interessaram mais, se alguma nova eu terei fixado, foi sempre por essa precisão que tem o amante verdadeiro, de conhecer a quem ama. Não tanto pra compreender o objeto amado em si mesmo, como pra se identificar com ele e milhormente poder servi-lo e gozar. Eu digo que, apesar de todas as notas juntadas pra esclarecer 
ou facilitar o caminho dos estudiosos, este livro não chega a ser uma obra de estudioso, porque é por demais obra de amor. Recolhendo e recordando estes cantos, muitos deles tosquíssimos, precários às vezes, não raro vulgares, não sei o que eles me segredam que me encho todo de comoções essenciais, e vibro com uma excelência tão profundamente humana, como raro a obra de arte erudita pode me dar. [...]. (ANDRADE, 1984, p. 388; MA-MMA- 074IEB/USP/SP).

Já na década de 20, Mário de Andrade estava consciente de que vivia em um mundo cada vez mais direcionado para a desaparição das autenticidades culturais, logo transformadas em peças de museus. Esse divórcio entre o contexto de produção e a obra de arte que consagra o museu era uma constante na reflexão de nosso autor. Não é por acaso que em Macunaíma, o maior antagonista do herói é um colecionador. Na rapsódia, o herói persegue o colecionador Venceslau Petro Pietra para evitar que seu amuleto mágico, a muiraquitã roubada, se transformasse em uma mera peça de museu. Trata-se de um projeto gigantesco de preservação da autenticidade cultural do Brasil que o escritor assumiu como missão pessoal. Macunaíma é a realização deste projeto para que um dia, quando tudo tivesse desaparecido ou sido transformado pela ação predatória da civilização de consumo, a rapsódia pudesse ser uma alternativa pra recordar um Brasil autêntico, nos feitos e aventuras do herói de nossa gente, Macunaíma. Não por acaso, o desfecho da rapsódia é tão melancólico e triste.

É como desdobramento desse contexto, no âmbito da "atitude interessada", das reflexões e da postura obsessiva de Mário de Andrade de levar a termo esse projeto de preservação da "autenticidade" da cultura brasileira, que ele projeta, planeja, esboça, organiza suas recolhas e estudos, e inicia as escrituras de sua obra "grandiosa" Na pancada do Ganzá. A vida, no entanto, não Ihe reservaria tempo para concluí-la.

Na pancada do Ganzá, então, consistia num projeto (obra em preparo) em que Mário de Andrade pretendia reunir o amplo material poético-musical-coreográfico recolhido em suas viagens etnográficas, apoiando-se nos estudos e coletâneas existentes. Esse cancioneiro deveria se escorar de segurança teórica e terminológica, daí a confecção simultânea de outra obra de fôlego, o Dicionário Musical Brasileiro, iniciada no mesmo ano, em 1929. Para estas obras, o autor indicaria um processo de trabalho na relação das "Leituras iniciadas prá Na pancada do Ganzá" cujo registro em seu arquivo no Instituto de Estudos Brasileiros/USP consigna uma bibliografia de 837 obras. 
Para os objetivos deste artigo, que apenas se propõe a apontar as possibilidades de um novo diálogo cultural entre Mário de Andrade, artistas e músicos populares, inclusive Pixinguinha, apresentamos uma pequena síntese do que se anuncia na pesquisa de arquivos e obras que referendam o projeto do musicólogo $\mathrm{Na}$ pancada do Ganzá, em especial, as considerações de Oneyda Alvarenga quando da organização e publicação de parte do acervo do cancioneiro em Danças Dramáticas (3vols), Música de feitiçaria no Brasil, Os Cocos e As melodias do boi e outras peças, a fim de contextualizar o que mais particularmente nos interessa que é o acervo dos Fundos Villa-Lobos ${ }^{4}$ inseridos nos arquivos da obra em preparo. Indicado na bibliografia de Na pancada do Ganzá com o ํㅡ 59 e incorporado como fonte de pesquisa de Mário de Andrade, esse acervo se destaca como um conjunto de produções poético-musicais populares, cuja "escuta", possivelmente, o faria desaguar na obra, como bem indicam os rastros do musicólogo pontilhados tanto pelas indicações de suas referências, quanto pelas marcas no processo poético-musical ${ }^{5}$ de suas considerações e notas críticas.

Segundo explicações de Oneyda Alvarenga, em Na pancada do Ganzá supõese que o Ganzá, instrumento muito difundido no nordeste e transformado em símbolo verbal do conteúdo do livro, deu-se em homenagem à admiração pelos cantadores de Cocos, em especial uma homenagem a Chico Antônio, alvo da admiração de Mário de Andrade que ainda lhe dedicou três crônicas de "O Turista Aprendiz" (10, 11, e 12 de janeiro de 1929), um artigo publicado em "A República", Natal, 27-1-1929, e doze rodapés no "Mundo Musical" da Folha da Manhã de São Paulo. A expressão "na pancada do Ganzá", definidora da função do instrumento como apoio não só rítmico, mas da invenção músico-poética em seu conjunto, aparece nos Cocos de Chico Antônio. E está referendada na nota $929^{6}$, nota de Mário de Andrade: "Vocabulário - Na pancada do Ganzá/ é uma poesia sobre a seca./ Lembrar que havendo já um romance e essa canção com meu título, só soube disso depois do titulo, que não é invenção minha, mas verso-feito popular./59, VI, 162" (ANDRADE, 1984, p. 490), isto é , consignado dos Fundos Villa -Lobos.

Assim, o entrelaçamento desses enunciados (práticas sociossimbólicas), nesse conjunto de "vozes" renovadas em sentidos diversos, respalda-se na linha teóricoanalítica que norteia este trabalho: o diálogo está presente em todo enunciado ${ }^{7}$, seja no oral, no escrito, no letrado ou não; e a polifonia, sua força suprema, traz um feixe de possibilidades no sistema da língua (enquanto produtora e produto de cultura) e 
um feixe de possibilidades conjunturais dialógicas na realização de um projeto enunciativo: "Aquilo que não responde a nenhuma pergunta não tem um sentido para nós, afastado do diálogo". (BAKHTIN, 2010, p. 381).

A escrita é a transcrição codificada das vozes, capaz de transmitir os sentidos desse diálogo ontológico, posto que, segundo Bakhtin, "ser é comunicar-se dialogicamente". No mundo de Bakhtin, a escrita é privilegiada justamente como um percurso capaz de traduzir a voz humana na medida em que é portadora dos sentidos da existência, preservando de modo específico suas modalidades, que ele caracteriza mediante metáforas relacionadas à voz e à música: polifonia, contraponto, orquestração, palavra a duas vozes, coro, tom, tonalidade, entonação, acento, etc., não no sentido estilístico tradicional como traços distintivos dos autores, mas como uma espécie de memória semântica e social. O enunciado é, dessa forma, metáfora da oralidade codificada por escrito, é uma unidade mínima que pode ser respondida no processo de comunicação dialógica. (BAKHTIN, 2010, p. 261306).

Analogamente, entendemos ser possível apreender a realização do "projeto enunciativo" de Mário de Andrade sob essa perspectiva: Na pancada do Ganzá é um enunciado polifônico, metáfora da oralidade e da tradição (suas fontes básicas) codificada por escrito, cuja orquestração de vozes, músicas, palavras, poesias, tonalidades, danças, espaços, enfim, práticas sociossimbólicas de um processo de comunicação dialógica, Mário de Andrade (o regente das vozes) buscou reunir e registrar a memória semântico-cultural de "brasilidade" da cultura popular brasileira.

Assim, apresentamos um sintético dossiê descritivo do esboço, da organização e dos registros (pesquisados nos arquivos do IEB e cotejados com as publicações de Oneyda Alvarenga) que nos chamaram a atenção na obra em preparo, enquanto pauta de um diálogo suspenso no tempo histórico, mas não esgotado e potencialmente passível de renovação no grande tempo da cultura. Esclarecemos, porém que, delimitado o recorte dos registros identificados para este artigo, buscamos captar sonoridades: a voz do autor que planeja e organiza, do crítico estudioso e apaixonado junto com vozes (harmoniosas ou dissonantes) que inspiram e sustentam a imaginação crítica de uma "escuta aberta", enquanto percepção desses acordes, "discursos poéticos do passado na sua qualidade profunda de permanecer em aproximação direta com este mundo onde estamos, mundo que 
somos e que não é um mundo de verdade, mas de desejo." (ZUMTHOR, 2007, p. 107).

Inicialmente, na caixa com os manuscritos e documentos dessa parte da obra o Prefácio - identificamos uma folha com pequeno registro do arquivo, sem, no entanto, apresentar o dossiê da catalogação, como em outras obras do acervo de Mário de Andrade ${ }^{8}$.

Os documentos encontram-se organizados em pastas e subpastas com os envelopes, folhas de caderneta em manuscritos, caderno com a bibiografia, recortes de jornais, capas usadas como suporte, por exemplo, uma capa de cartolina grande de uma publicação francesa: La Musique de Chambre/Revue semetrielle de Musique ancienne et modern-Piano, Paris,1924., aproveitada para guardar as notas do Prefácio, e outra de um Convite da Sociedade de Intercâmbio Cultural e o Grêmio Brasileiro de Cultura Japonesa de São Paulo para uma conferência, também usada como suporte de manuscrito. Segundo Oneyda, entre os documentos deixados por Mário de Andrade, existem dois planos reveladores do que seria o $\mathrm{Na}$ Pancada do Ganzá, se a obra imensa fosse levada a cabo. O primeiro em data parece este dividido em "três livros" ou setores cujos títulos encabeçam laudas independentes:

Na Pancada do Ganzá-/Prefácio (sublinhado).

Descrever com síntese viva os meus três meses de Nordeste como viagem. Descrever de modo geral o povo que gozei (Ler Euclides e outros) (citar casos típicos, passados comigo ou tradicionais, de psicologia nordestina.) Descrever as festas que apreciei. Estudar a decadência delas e atacar o conceito de progresso, os genéricos e os particulares cultos.

Descrever enfim os meus processos para tomada dos documentos.

(Fazer seguir ao prefácio)

Taboa de Referência (riscado a lápis)

Psicologia (riscado a lápis)

Notas sobre meus colaboradores ( sublinhado) (nomes iniciais, psicologia e observações técnicas sobre cada um ,menos sobre Chico Antonio e sobre Adilão, que virá nos capítulos deles)

Taboa de Referências

(indicar as abreviaturas todas)

Na Pancada do GanzálLivro Primeiro/ A Língua e a Poesia Na Pancada do GanzálLivro Segundo / A Música.

Na Pancada do Ganzál Livro Terceiro / Documentação / Boi/ Catimbó/ Melodias de Vária Espécie.

Nota- Desistir de capítulos especiais sobre Chico Antônio e Adilão que só vêm atrapalhar a boa distribuição do livro. A homenagem a eles fica nas referências individuais aos colaboradores. (ANDRADE, 1984, p. 13).

E em nota presa à folha, uma observação esclarecedora: 
Pancada do Ganzá- O milhor é após o prefácio contando a viagem, dar o estudo sobre a música recolhida. Dar em seguida os documentos em notas curtas no baixo da página e notas compridas (Psicologia, crítica, notações, etc), no fim. A cada capítulo precedendo o estudo geral do que a coisa trata. (ANDRADE, 1984, p. 13).

Segundo Oneyda, desta nota teria nascido a escolha definitiva do tratamento a ser aplicado aos vários documentos, onde surgem o prefácio, os livros I e II do projeto anterior se reúnem num só e o Catimbó desaparece. Também um outro lembrete deste segundo plano mostrando, com maior detalhe, sua destinação à análise geral das características musicais, poéticas e coreográficas dos documentos expostos nos demais setores da obra:

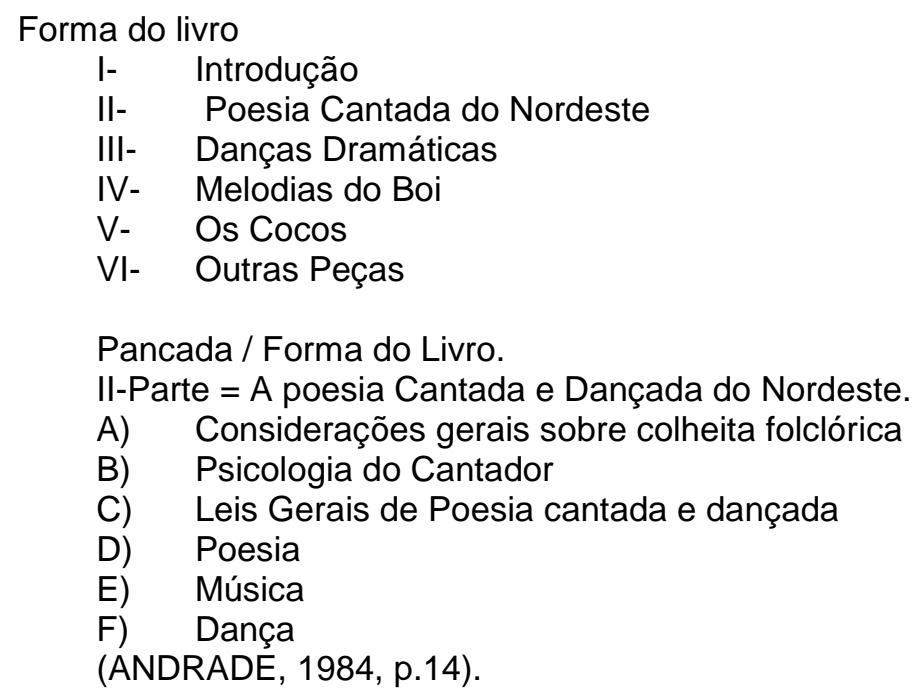

Feitas, então, tais observações no cotejo com a organização de Oneyda, na sequência, as pastas compostas com as anotações vão revelando o esquema planejado, o empenho de organizar os escritos e o esforço a ser empreendido pelo autor:

\footnotetext{
Pancada/ Estrutura do Livro/ No princípio de cada capítulo pôr uma nomenclatura, espécie de dicionário explicando o sentido das palavras técnicas usadas no Capítulo. Ex:

Poética Nordestina

Nomenclatura:

Romance: romance é um gênero de poesia em que se desenvolve intelectualmente um assunto qualquer- no geral um caso que pode ser lendário, tradicional, literário ou fato acontecido nas camadas populares.
} 
Moda: palavra vaga, ora significando uma poesia lírica, ora a melodia que acompanha essa poesia.

Etc, etc.(ANDRADE, MA-MMA-074-IEB/USP).

Folheando atentamente a bibliografia relacionada, consolidamos o que já é público e notório e que evidencia a polifonia presente no fazer literário e crítico do autor: reverberam múltiplas vozes de autores, poetas, estudiosos, além das vozes populares trazidas à cena por conta de suas recolhas, e de colaborações de amigos, que não desconheciam sua seriedade como intelectual e, sobretudo, o seu amor pela cultura brasileira. Na relação bibliográfica identificamos nos números 58 e 59 dados significativos para a pesquisa: a diversidade de um acervo composto de outros acervos, denominados de "fundos".

58-Fundos Folclóricos paulistas, colecionados por Paulo Duarte, com a colaboração dos srs Tomé Teixeira (Itararé), Francisco Damante (Perdões), José Honório de Sillos (S. José do rio Pardo), João Cortez Rennó Ferreira ( S.Bento de Sapucaí), Sud Menucci ( Porto Ferreira), Palmira de Oliveira(Casa Branca), Benedito Pires de Almeida (Tietê) Correia de Mello ( São Paulo), Leopoldo de Amaral( Campinas).

59-Fundos Villa-Lobos. (ANDRADE, MA-MMA-074-IEB/USP).

$\mathrm{Na}$ indicação dos Fundos Villa-Lobos não há detalhamento como no anterior. Pelos critérios que se pode inferir da organização de Mário de Andrade, os documentos dados por Villa-Lobos estavam desorganizados e não continham, em sua maioria, referências de autoria (como posteriormente ficou comprovado). A essa altura, uma questão se colocava: Será que Mário tinha conhecimento de que nesses fundos havia recolhas poético-musicais pesquisadas por Pixinguinha e seu grupo? Haveria, mesmo, alguma indicação dessas vozes na recolha dos Fundos? Posteriormente, consideramos essa possibilidade pelas marcas apresentadas em alguns textos do acervo, como homenagens e parcerias com João Pernambuco, Donga e os Oito Batutas, além do recorte de jornal da entrevista ${ }^{9}$ de Villa-Lobos constante também no acervo do musicólogo e, ainda, as cartas do maestro e de Arnaldo Guinle.

O quantitativo indicado e a diversidade das leituras de autores nacionais e estrangeiros da bibliografia inicial anunciava a dimensão do projeto de Mário de Andrade; suas intenções, desejos e o esforço que já de início empreendera e o que estava por fazer. Isso sem contar os Fundos como acervos reunidos dentro de outro acervo. Sabe-se por trabalhos posteriores que nos Fundos Villa-Lobos há 633 
documentos: registros de recolhas, alguns repetidos, entre literatura popular em folhetos, romances, desafios, músicas e partituras. Infere-se, pelos estudos já empreendidos e consulta às pastas, que Villa-Lobos reteve consigo grande parte das partituras reunidas nessa recolha. Pode-se deduzir que aí estaria expressa a maior contribuição de Pixinguinha, haja vista o que está registrado no depoimento de Donga ao MIS, quanto às motivações que o levaram a insistir com Arnaldo Guinle na ida do músico nas viagens combinadas: Pixinguinha era um dos poucos músicos populares que dominava notação musical. Segundo Donga, "Pixinguinha trouxe tudo escrito, tudo bem feito e o dr. Arnaldo ficou satisfeito" (Depoimento ao MIS-RJ) a ponto de o mecenas financiar nova viagem do grupo em 1922, agora a Paris.

Ainda nessa pasta do arquivo encontra-se uma segunda bibliográfica feita por Mário de Andrade em datiloscrito, em pasta de cartolina amarelada pelo tempo, onde se lê: "Bibliografia". Seu conteúdo, folhas numeradas somente de 1 a 28 indicam a mesma listagem feita no caderno, só que datilografando as numerações e as indicações bibliográficas até o número 695. Depois continua a listagem a caneta de tinta preta até 0 no 837. Observa-se no confronto entre as duas listagens 0 acréscimo na segunda lista de mais cento e cinco obras, de 732 da primeira até 837 da segunda, o que se pode concluir que à medida que avançava no projeto, ia ampliando consideravelmente as leituras e o rigor nos estudos.

$\mathrm{Na}$ sequência, as demais pastas contêm envelopes com fichas de anotações diversas. Trata-se de citações, observações do autor, explicações complementares aos termos técnicos, especificações vocabulares relacionadas ao tema da parte indicada. Destacamos alguns exemplos da pasta em que organiza a "terminologias técnicas":

Terminologia Técnica (2) Noções pra ter sempre em vista no escrever o livro e no criticar os documentos (ANDDRADE, MA-MMA-074-IEB/USP).

Ainda uma citação relacionada a essa nota, tirada da referência da bibliografia (131-Curt Sanchs -Geist und Werden der Musikinstrument-ed.Dietrchi Reimer . Berlim 1929.p. 4) explicita uma opção teórico-analítica do musicólogo de se afastar do "evolucionismo" ainda vigente na época em estudos sobre o folclore. 
temer aqui também como pior inimigo de qualquer pesquisa, é a plausibilidade. É um perigo, dum ponto- de -vista atual, mesmo estrangeiro, de introduzir a ideia evolucionista no assunto, quando pelo contrário ela devia primeiro ser tirada dele". (ANDRADE, MA-MMA-074-IEB/USP).

No mesmo envelope, outra nota evidencia sua preocupação didática para tornar o livro inteligível:

Pancada/Talvez fosse bom querendo especificar um texto cantado ou dança ou etc. dizer que é: "de função sexual" (os amorosos), "de função econômica" (os que tratam de ganhar a vida), "de função industrial" (os que tratam de trabalhos quotidianos), "de função hedonística" (os que tratam de divertimento puro), "de função moral" (os que tratam do beneficiamento da alma) etc." (ANDRADE, MA-MMA-074-IEB/USP)

As demais notas sobre o termo "técnico" vão indicando seu aprofundamento nos estudos etnográficos e sua leitura atenta dos autores selecionados, com vistas a suas formulações teóricas sobre a cultura popular.

\section{Superstição}

No princípio esta palavra significava "o que persiste de idades passadas" $n^{\circ}$ 91 p 83

Pancada/ Tecnologia

Leis de Raul Rosières

1- Povos de mesma capacidade chegam a criação de ideias iguais ou idênticas.

$2^{\circ}$ Lei de Transposição (sublinhado em vermelho): Quando a fama dum herói fraqueja as suas lendas vão adorar outros heróis mais famosos.

3 ․ Lei da adaptação (sublinhado em vermelho): toda lenda transplantada se adapta às condições etnográficas e sociais do meio novo./ 265-I-117.

Terminologia

Lei de similitude (Frazer) é que todo semelhante obriga a um semelhante ( similia similibus).

Lei de contágio- é a pelas quais duas coisas que estiveram em contacto continuam com ação uma sobre a outra mesmo cessado o contacto (Frazer) n 181 p. 15 (James George Frazer- Le Rameau D’Or. Paul GeuthnerParis, 1924).

Terminologia

"representação coletiva"

Não é apenas a ideia, a imagem (representação no sentido comum) mas essa imagem acompanhada e diluída em desejos, anseios, temores, religiosidade, etc."les réprsentations collectives que s'y rapportent sont impératives, sont tout autre chose que de purs faits intellectuels" $n^{\circ} 105$ p.30).

A palavra foi empregada nesse sentido a primeira vez por Lévy Bruhl que a explica. $n^{\circ} 105$ p.28"( Lévy-Bruhl-" Les fonctions Mentales dans les Sociétés Inférieures", $8^{a}$ ed. Felix Alcan, Pais, 1928. (ANDRADE, MA-MMA-074IEB/USP). 
A partir dessas pastas que delineiam uma organização inicial, seguem outros conjuntos de pastas no arquivo em que se encontram anotações diversas, artigos de jornal, e notas com as respectivas indicações do tema ou assunto, em subpastas, que se aplicariam para o desenvolvimento da respectiva parte. Observa-se pela leitura dos registros seguintes a relação de elementos configuradores da "Psicologia do Cantador": sua "sabença" sua resistência às adversidades, especialmente à seca; o sertão como seu lugar de origem, seu trabalho no engenho, sua brasilidade. Desloca-se assim o autor, para dar "voz" a essa configuração. Segundo Oneyda, Mário de Andrade nada fez para a parte II (A Poesia Cantada e Dançada no Nordeste), em termos de elaboração escrita, "justo a mais importante, visto que seria os do juízos críticos, iluminadores e abridores de caminho"( 1984, p.15). Entendemos, entretanto que, mesmo de seu formato-esboço, muito se pode apreender da seleção de seus registros, nos quais identificamos, se não uma análise poética estruturada formalmente como resultado de seus estudos, ao menos uma poética que se desentranha das particularidades dos enunciados e se revelam no sabor dos saberes selecionados (que não são neutros, nem gratuitos), na linha do que Zumthor nos coloca:

\footnotetext{
A ciência parte de uma observação; o saber de uma experiência... que falta articular em discurso: isto é, em testemunho [...], o saber procede de uma confrontação comovente com o objeto, de um esboço de diálogo com o que ele tem de único [...] é menos centrado no próprio conhecimento que no desejo de conhecer. (ZUMTHOR, 2007, p. 100).
}

Nesse sentido, parece-nos que o "querer saber" de diversas origens se cruza ao "querer saber" de Mário, a sua escuta à cultura popular, no estatuto dinâmico do diálogo com esses registros. Seguindo, então, as trilhas do arquivo, vamos "ouvindo" esses saberes: o do autor e de suas recolhas:

\author{
Psicologia'/2 / "Cantadores \\ Fortaleza de Cantador \\ Chico Antonio \\ Adilão". \\ Cantador/Sabença/ № 59, IX, 86. \\ Pois, meu colega, eu lhe digo, \\ Quem canta deve estudar \\ Gramática e geografia \\ Para quando precisar \\ Não conhecendo as palavras
}


Como é que se pode explicar!

(ANDRADE, MA-MMA-074-IEB/USP).

Mário parece fundamentar essas anotações sobre a "psicologia do cantador" com um artigo de Luiz Câmara Cascudo (recorte anotado a lápis por Mário: DO DIÁRIO DE NOTÍCIAS/RJ-27/IX/42) no rodapé "Etnografia e Folclore" consagrado a Inácio da Catingueira e seu duelista Romano da Mãe que num dia de feira, no mercado de Patos, em 1870, duelaram e cantaram oito dias seguidos.

Além disso, outras observações sobre o homem nordestino vão surgindo nas fichas e notas, relacionadas à "Psicologia nordestina". Nessas notas, citações retiradas de leituras de estudiosos e também da literatura, do cordel popular e comentários críticos diversos, Mário de Andrade relaciona elementos que apuram a "psicologia nordestina": cordialidade, hospitalidade, honestidade, desonestidade, alegria, apego à terra ou "o amor ao torrão" cuja observação crítica questiona o senso generalizado de "louvor lírico" do sertanejo que justifica seu retorno ao sertão, destacando motivações socioculturais para a inadaptação do sertanejo à civilização do sul.

\begin{abstract}
Psicologia Nordestina / O "amor ao torrão" que fez o paroara amazônico voltar pró Nordeste e de que se faz um padrão de louvor lírico e sentimental do sertanejo, talvez deva ser tratado mais discretamente. Antes de mais nada isso não representa propriamente a verdade. Na Amazônia mesma há quantidade vastíssima de nordestinos que ficaram lá, vivendo a vida civilizadamente precária de vilejos e de rio. E vá se perguntar então pros nordestinos que vieram pro Sul (aliás Centro) em principal médicos, doutores, e principalissimamente empregados- públicos se voltam, se estão voltando pro Nordeste. Vivem todos, é certo, num saudosismo admirável e exaltado das doçuras naturais lá da terra, maravilhosa, mas é também incontestavelmente certo que 99 por cento não têm a mais mínima intenção de voltar. Mas observemos os analfabetos e gente do povo. Esses também numa percentagem vitoriosa não pretendem nunca voltar. Mas há sempre um grupo numeroso que volta. São os retirantes da seca que buscam o Brejo no tempo de desgraça e depois voltam pro seu sertão. São ainda os "sampaleiros" ou "sãopauleiros", o que veio pra S. Paulo e depois volta pro seu sertão do São Francisco, e leva obrigatoriamente, pra provar que é sampaleiro a sanfona debaixo do braço. Sim, voltam pro sertão aspérrimo e comove muito pensamentear nessa volta. [...] (ANDRADE, MA-MMA-074-IEB/USP).
\end{abstract}

$\mathrm{Na}$ sequência em que vamos identificando referências pertinentes ao tema, destacam-se registros sobre a seca, entre os quais dois recortes de jornal sobre o assunto, anotações críticas de Mário de Andrade, cujas considerações sociológicas são ambiguamente contaminadas de tom moralista, e notas, citações e versos populares reiterando referências aos Fundos Villa-Lobos. 
Seca (Em psicologia do nordestino tenho mais considerações).

Acho um verdadeiro perigo essa conversa lírica do sertanejo em herói, só porque vive no sertão, sofre os horrores da seca, foge mas volta quando 0 verde volta. É sim uma espécie de heroísmo porque afinal das contas a vida proletária é sempre uma espécie de heroísmo, seja a do sertão seja a paulistana. Mas o heroísmo daquela implica também o abandono de certos desejos humanos, de certas ambições, de certas coragens que podem depor fortemente contra a valorização do homem do sertão. Se o sertanejo é um herói, convém verificar com franqueza que o heroísmo dele está muito próximo da animalidade, do abatimento moral, da modorra das virtudes que obrigam a progredir e conquistam materialmente 0 bem-estar da vida. (ANDRADE, MA-MMA-074-IEB/USP).

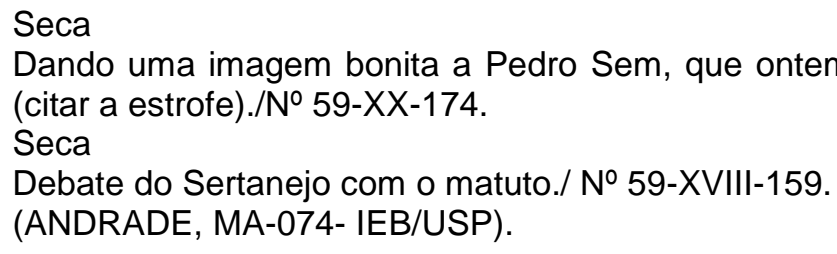

Percorrendo as últimas pastas e as subpastas do arquivo, concluímos que todo conjunto são notas marcadoras de planos relativos ao Na Pancada do Ganzá: o início do prefácio, fichas e notas para sua elaboração, um esquema para o índice e folhas escritas que articulam partes de uma introdução para o incompleto prefácio. Retomamos, então, mais alguns registros que alinhavam esse arquivo, sem perder de vista que, a despeito de seu inacabamento, essa obra planejada e iniciada, (materializada nos arquivos) tornou-se um locus de mediação (em suspenso?) a mercê daqueles quantos queiram retomar seus fios, rearranjar seus escritos, afinar seus acordes, para auscultar sua melodia, seus contrapontos do imaginário poéticomusical da cultura popular brasileira a que tão intensamente Mário nos remete com sua literatura, seja ela expressão "acabada" ou uma promessa...

$\mathrm{Na}$ cadência das notas, revelam-se os desdobramentos de um Prefácio inacabado, escrito em seis páginas do qual reproduzimos partes:

Pancada do Ganzá/Prefácio/ Livro que não é folclore científico. Não passa duma disposição amorosa, e se comparo e critico às vezes é por essa precisão natural de compreender e fazer compreender pelo menos na medida do meu amor (ANDRADE, MA-MMA-074-IEB/USP).

Pancada do Ganzá/l/ Introdução.

Este não é um livro de ciência, evidentemente, é um livro de amor. Estarão sempre muito enganados os que vierem buscar nele a sistemática dos fatos musicais e poéticos do Nordeste. Eu não tive nunca, nem poderia ter pela falta de estudos organizados, a pretensão de ir no rasto dos fenômenos humanos, até aquele fundo profundo que retrata os homens do nosso tempo dentro do esquema das coletividades quase imemoriais. Deus me livre de negar que a 
ciência seja por sua vez fenômeno de amor, mas "conhecer" no sentido de decidir da Verdade, é um verbo que me assusta um bocado. [...]

[...] Quando se tem um coração bem nascido, encarar com seriedade os abusos do povo, uma coisa dessas comove muito e a gente não esquece mais. Do fundo das imperfeições de tudo quanto o povo faz, vem uma força, uma necessidade que, em arte, equivale ao que é a fé em religião. Isso é que pode mudar o pouso das montanhas. É mesmo uma pena, os nossos compositores não viajarem o Brasil. Vão na Europa, enlambusam-se de pretensões e enganos do outro mundo, pra amargarem depois toda a vida numa volta injustificável. Antes fizessem o que eu fiz, conhecessem o que amei, catando por terras áridas, por terras pobres, por zonas ricas, paisagens maravilhosas, essa única espécie de realidade que persisto através de todas as teorias estéticas, e que é a própria razão primeira da Arte: a alma coletiva do povo. Teriam muito mais coisa a contar. Conquistariam o direito incontestável do seu Anastácio que chegou de viagem, o direito que eu tenho agora. Porque não basta saber compor. Carece ter o que compor. (ANDRADE, MA-MMA-074-IEB/USP).

Entremeando a introdução, Mário de Andrade desloca-se da "psicologia do nordestino" para a crítica ao estaduanismos e separatismos brasileiros, que levavam os Estados nordestinos a terem "birrinhas uns com os outros" e todos se juntarem "pra ter birra de São Paulo". E nessas considerações referenda um poema dos Fundos Villa-Lobos, cujo autor diz ignorar, mas que posteriormente foi identificado em sua coleção de folhetos populares pela pesquisa de Ruth L. Terra.

[...] Há porém dentro de tudo isso, que se dá entre nós apenas na gente alfabetizada, que é mais ou menos cômico, não tem importância e não vai além do falar mal, uma coisa tristonha. É que se todos têm birrinhas uns dos outros, todos se ajuntam pra ter birra de S. Paulo. Mas que o sentimento estava próximo a se generalizar mesmo no povo, pela boca dos cantadores, prova o admirável romance de "O Povo na Cruz" $(59,1 \mathrm{II}, 116)$ de que ignoro o autor. Eis as estrofes que interessam:

[...]

Não há mesmo quem resista

Estes impostos de agora;

Diz o Governo: Que tem

Que morra tudo em ua hora?

Quando o Norte se acabar

Eu boto o bagaço fora.

E si não houver inverno.

Como o povo todo espera.

De Pernambuco não fica

Nem os esteios da tapera.

Paraíba fica em nada.

Rio Grande desespera.

O Rio de Janeiro hoje

Parece um grande condado.

Ri-se o rico, chora o pobre

Lamentando o seu estado;

Diz o Governo: Eu vou bem,

Tudo vai do meu agrado.

São Paulo, o Governo 
É primor de criação,

Eu acho parecido

Com sítio da maldição,

Aquele que Judas comprou

Com ouro da traição.

(ANDRADE, MA-MMA-074 IEB/USP).

Note-se nesse registro como é original a natureza das relações dialógicas. A questão do dialogismo interior, o limiar das fronteiras ente os enunciados que, no caso, precede as formulações do autor balizadas em suas observações e experiências e o encontro com o enunciado/saber que sai da "boca do cantador" e se cria na prova poeticamente irrefutável da "birra contra São Paulo", desaguando no prefácio inconcluso.

Assim, no arremate deste percurso do arquivo MA-MMA 074, selecionamos uma pequena nota indicativa, no esquema de Mário de Andrade, que finalizaria o prefácio:

\begin{abstract}
III Final
Prefácio / Enfim paro aqui e principio mostrando os tesouros que ajuntei. Não tenho a mínima ilusão sobre o meu pouco trabalho e prazer formidável que tive coligindo estas coisas. Seria mesmo quase apenas um dar gosto ao tempo, se não fosse o verdadeiro ganho de vida em amor e entusiasmo com que trabalhei. Só me resta uma certa tristurinha indecisa de não ser profissional no assunto e não ter valorizado com mais base os tesouros de meu povo. Mas aí ficam pelo menos os tesouros pra quem milhor os possa engrandecer. "Tudo o mais vem a ser nada" (1), como no verso do cantador. (ANDRADE, MA-MMA-074-IEB/USP).
\end{abstract}

\title{
2 UMA NOVA PAUTA POÉTICO-MUSICAL NOS FUNDOS VILLA-LOBOS.
}

Entre o acervo de notas de trabalho, bibliografia, recortes de jornais e documentos diversos reunidos para preparação da obra, insere-se um conjunto expressivo de manuscritos e datiloscritos em 22 pastas, denominado Fundos VillaLobos.

Os Fundos Villa-Lobos ${ }^{10}$, denominação criada provavelmente por Mário de Andrade, integram um projeto que visava sistematizar e publicar uma produção popular brasileira, sendo posteriormente incorporados como fonte de pesquisa por Mário de Andrade. Segundo Ruth Terra, que fez uma primeira apresentação e catalogação dos $F V L$, o acervo é diversificado: 
[...] as pastas contêm 633 textos, alguns copiados mais de uma vez, num total de 527 diferentes obras. A maior parte dos textos são de literatura popular em verso do Nordeste (folhetos): romances, desafios, e poemas de época. Os demais são trovas, poemas popularescos (de Catulo da Paixão Cearense) letras de música popular urbana e alguns poemas de autores como Castro Alves e Tobias Barreto, seguidos de paródias. Os textos não trazem indicação de autoria, local e data de publicação, salvo exceções. (TERRA, 1981, p. 3).

Em síntese, as pastas dos FVL reúnem poemas de folhetos, sobretudo poemas de época, romances que abrangem histórias da tradição como Imperatriz Porcina, contos maravilhosos, e variantes ou versões de poemas, alguns ainda hoje não editados. Esses textos revelam particular interesse aos estudos de como os poetas populares trabalham um mesmo tema da tradição oral, fonte comum a todos. Além disso, permitem uma visão de toda a temática desta literatura e dos seus autores nas duas primeiras décadas do séc. XX. Destaque-se também que se encontram no acervo dos $F V L$ textos de difícil localização, como, por exemplo, poemas de época que trazem "queixas gerais" - que denunciam a carestia, os baixos salários dos trabalhadores no campo ou cidade, e sobretudo a miséria dos retirantes na seca e no trabalho do engenho, os desmandos dos poderosos e outras mazelas - ou ainda aqueles sobre as "salvações do norte"; além de inúmeros desafios ou o Marco Paraibano completo. Aí, encontram-se textos de autores diversos: Leandro Gomes de Barros, Francisco das Chagas Batista, João Martins de Athayde, Pacífico Pacato Cordeiro Manso, dentre outros. (TERRA, 1981, p. 4-5).

Sabe-se, até o momento, que esse conjunto foi, em parte, constituído por recolhas poético-musicais empreendidas entre 1919 e 1921 pelos Oito Batutas, conjunto musical do qual faziam parte Pixinguinha, Donga, China e João Pernambuco (este último, incorporado ao grupo nas viagens). Tal pesquisa, financiada por Arnaldo Guinle, grande mecenas cultural da época foi, posteriormente, repassada a Heitor Villa-Lobos para que o músico organizasse e elaborasse uma antologia poético-musical folclórica ${ }^{11}$. Entretanto, consta que 0 maestro envolveu-se em outros projetos e substabeleceu sua responsabilidade a Mário de Andrade por volta de 1929, conforme intenção revelada em carta ao musicólogo, em dezembro de 1928:

[...] Creio que D. Olívia já te falou dos meus projetos em entregar-te todo meu compromisso para acabar a Alma do Brasil, assim como todo o meu imenso material folklore. Como não deves ignorar tenho todo $01^{\circ}$ volume que tem uma longa introdução e um minucioso estudo documentado sobre 
nossos índios. Porém reconheço que toda essa obra é fraca, porque não possuo a capacidade sintética de historiador, nem tenho tempo para cansar a minha imaginação (que está inteiramente voltada para um outro assunto) em consultar livros e exercitar-me para o aperfeiçoamento de linguagem clara e curta que é o que mais requer as obras nesse gênero.

Tu és o único que pode assumir essa responsabilidade. E se achares útil, meu concurso, estarei sempre as tuas ordens. [...] (VILLA- LOBOS, Paris, 25/12/1928. MA-C-CPL n6994. ARQUIVO IEB/USP; cf. Anexo 42).

As pastas dos $F V L$, entretanto, não contêm toda documentação reunida por Arnaldo Guinle. Em entrevista de 8/1/1925, concedida a Alcântara Machado para o Jornal do Comércio de São Paulo ${ }^{12}$ no Salão do Mappin, Villa-Lobos declara que o mecenas o havia convidado em Paris para organizar e sistematizar grande quantidade de dados e documentos de folclore que iam "além de mil", dá informações sobre o projeto e encerra a entrevista com um apelo aos brasileiros:

\begin{abstract}
$[\ldots]$
Dr. Arnaldo Guinle me convidou, em Paris, para organizar e sistematizar o nosso folclore de música e poesia, sobre o qual já dispunha ele de grande quantidade de dados e documentos, mandados colher em todo o Brasil e que lhe custara muitos contos de réis. [...]

Para levar a cabo esta importante obra regionalista, eu solicito o concurso de todos os brasileiros pedindo-lhes que me enviem para a casa Arthur Napoleão, no Rio de Janeiro [...] tudo que diz respeito ao nosso folclore. ("Villa-Lobos e o Folclore Nacional". Jornal do Comércio de São Paulo, 8/1/1925. apud TERRA, 1981, p. 5).
\end{abstract}

Confrontando as informações dessa entrevista com o depoimento de Donga ao MIS/RJ, informando que eles trouxeram músicas escritas, e que "Pixinguinha trouxe tudo escrito, tudo bem feito", e considerando que nos $F V L$ há apenas 4 partituras ${ }^{13}$, o que se pode inferir é que Villa-Lobos entregou a Mário de Andrade apenas a parte referente à poesia. E embora o fato não invalide a importância da participação dos músicos e de Pixinguinha, em particular, na recolha sensível de uma amostragem tão ampla da literatura popular daquele período inicial, muito provavelmente, no acervo musical guardado por Villa-Lobos se explicitariam as contribuições mais diretas de Pixinguinha para a pesquisa folclórica, pois o que o distinguia entre os músicos do grupo era sua competência para fazer notações musicais. Além disso, é possível que Villa-Lobos tenha mandado datilografar alguns poemas de folhetos ou de obras de folclore constantes nas pastas, e que nos Fundos constem outros textos além daqueles reunidos por Donga, Pixinguinha e João Pernambuco ${ }^{14}$.

Importa lembrar aqui que há no acervo indicações de que Mário de Andrade fez uma "organização" dos conteúdos e das pastas, numerou-os e empreendeu uma 
pequena classificação aos textos como "Desafios", "Romances Narrativos", "Romances históricos" (o que hoje se denomina poemas de época), "Romances líricos", "ABCs", "Trovas”, "Glosas e motes", "Gírias e diálogos cantados” (TERRA, 1981 , p. 4). Por outro lado, apesar de indicar em cada título a pasta correspondente e se este era encontrado em folhetos de sua coleção, o autor não fez distinções entre os poemas de folhetos, poemas "popularescos" e paródias, do que se pode inferir que aos textos como fontes de pesquisa não foi atribuído valor esteticamente hierárquico.

Sabe-se que no projeto esboçado da obra Na pancada do Ganzá, Mário contemplaria uma parte à poética nordestina que denominou, preliminarmente, " $A$ Poesia Cantada e Dançada do Nordeste". Dessa parte o que se tem são notas e anotações, marcas de suas leituras e pesquisa de termos populares, modalidades musicais, expressões e provérbios, vocabulário, algumas considerações sobre a colheita folclórica, sobre a psicologia do cantador, estabelecidas no esboço do prefácio e na relação de notas dos temas. Mário não chegou a escrever sobre essa parte da obra que, certamente, seria a mais importante para os estudos literários.

Para os objetivos deste artigo, porém, dentre às questões possíveis de serem levantadas, entre tantas que surgem em uma visada sobre os $F V L$, diz respeito ao encontro dialógico de duas culturas, mediado pelo acervo recolhido: por um lado a de Mário, intelectual erudito, estudioso incansável da cultura popular, servindo-se de recolhas de músicos populares, como fonte de seu processo crítico e criador, incorporando e apurando saberes de sua própria cultura, projetando e iniciando a produção de uma obra pelas vias da compreensão criativa entre elas; por outro lado, a dos músicos populares, na sua dupla contribuição tanto como pesquisadores de um campo abrangente da poética-musical popular da época, quanto como artífices de práticas sociossimbólicas de seu próprio campo cultural.

Observemos o desafio abaixo, produzido no calor das homenagens aos Oito Batutas e ao Donga, que registra sua coautoria na música e ainda a Nota de Mário de Andrade transcrita da cópia em datiloscrito.

\footnotetext{
Desafio de Mané Pequeno com cumpade Antonico Música de Ernesto dos Santos (Donga)

"Escripto por Eduardo Faria, especialmente para os 8 Batutas do autor ao Ernesto dos Santos"
} 
Cumpade você me diga

Porém sem sahi dahi

(Se há coisinha mais boa

Que um copo de paraty) Bis.

Pelo que vejo cumpade

Você qué desafiá

Pois antão feche o seu corpo

Vá logo se confessá

Pois está morto comigo

Se principia a cantá.

Eu canto de noite e dia

$E$ quem fô mais cantado

Que venha em riba de mim

Só pra vê o meu valo

Não tenho medo de home

Que home também eu sou.

Eu conheço muita gente

Que diz ser valente até

Mas na hora do baruio

É valente, mas no pé

Corre mais que um veado

Tem mais medo que muié.

Pois antão cumpade veio

Me arresponda o que pregunto

Porque quando a gente morre

Muda nome prá defunto

Me arresponda ao pé da letra

Sem porém fugi do assunto

Isso cumpade arrespondo

Sem o meu sabê profundo

Se você dissé pruque

Tanta mardade há no mundo

Embatuque amigo veio,

Embatuque e vá ao fundo

Proque há tanta mardade

Eu lhe posso arrspondê

Se você dissé agora

Sem fugi, sem escondê

Pru que é que Deus existe

E muita gente não crê.

Cumpade prá esta progunta

Eu posso resposta dá

Si você disse pruque

Quem não tem voz qué cantá

$\mathrm{E}$ quem não pode c'as moda

As moda qué inventá.

Eu não gosto de negaça

Nem quero contá história

Mas conheço um burrico

Que só gostava de espora 
Era mêmo do seu corpo

E contava a mema história.

Essa sua valentia

Agora de certo foi-se

Bem minha vó me dizia

Que machado não é foice

$\mathrm{E}$ quem andava em cocheira

Estava sujeito a coice.

Não insurte desse modo

Um home como eu de bem

Só pruque perdeu a seisma

De sê cantado também

Vá pros inferno meu veio

Que lá você se dá bem.

(Fecha o tempo- solo)

(FUNDO MÁRIO DE ANDRADE, Fundos Villa-Lobos, pasta 13, manuscrito. ARQUIVO IEB/USP).

Este Desafio composto de uma quadra refrão mais dezoito estrofes de seis versos, totalizando dezenove estrofes, está no FVL em duas vias: em datiloscrito na pasta 2 e em manuscrito na pasta 13. Além da coleta dos músicos, o texto evidencia a interação dialógica no processo de criação do texto poético- musical e, na mediação do acervo, a outra "voz", a da recepção recuperada no registro de Mário de Andrade:

Nota de M.A- Muito bom pela esperteza de não responder às perguntas e tem estrofe genial. (FUNDO MÁRIO DE ANDRADE, Fundos Villa-Lobos, pasta 2, ARQUIVO IEB/USP).

Feito esse apanhado geral, o que se apreende é que as relações dialógicas são bem mais amplas que o discurso dialógico comum. Nosso entendimento é que, sob esse ponto de vista, Mário de Andrade assumiu a recepção da recolha dos Fundos Villa-Lobos como um entendedor participante do diálogo, e como observador/entendedor integrou sua observação como componente do objeto observado. Sua compreensão criativa tornou-se elemento constitutivo do enunciado total; o conjunto poético-musical tornou-se também sua pauta de compreensão responsiva, abrindo caminhos que não se detêm na compreensão imediata, mas abre caminhos mais a frente, de forma ilimitada. 
Nessa perspectiva, esse diálogo cultural, mediado pelos $F V L$, revela, tal como a "pancada no Ganzá", a expressão definidora da função de apoio não só do ritmo, mas de toda a invenção músico-poética do acervo em seu conjunto.

\section{CONSIDERAÇÕES FINAIS}

Por tudo que se apresentou até então, pautamo-nos no "projeto enunciativo" de Mário de Andrade, cuja metáfora semântico-cultural de "brasilidade" da cultura popular brasileira está presente tanto nos arquivos de Na pancada do Ganzá quanto no acervo dos Fundos Villa-Lobos, na intenção de nos fixarmos na "escuta" para as histórias e os dados que neles se entrelaçam e seus sentidos polifônicos que procedem do movimento, da pluralidade, da ressonância das vozes transgressoras que se inserem a todo o momento nos manuscritos de Mário, nos registros dos músicos populares, na intervenção de outros atores na constituição e no percurso desses acervos que se fizeram /fazem ouvir, pois "a leitura do texto poético é a escuta de uma voz. O leitor, nessa e por essa escuta, refaz em corpo e espírito o percurso traçado pela voz do poeta: o do silêncio anterior até o objeto que the é dado, aqui sobre a página". (ZUMTHOR, 2007, p.87).

\section{NOTAS}

${ }^{1}$ Mestre em Literatura pelo Programa de Pós-Graduação em Literatura. Este artigo resulta de pesquisa realizada junto ao Grupo de Estudos em Arte, Literatura e Mídias (Grupo LIAME).

2 Doutor em Literatura. Professor do Programa de Pós-Graduação em Literatura (PósLIT - UnB). Líder do Grupo de Estudos em Literatura, Arte e Mídias (Grupo LIAME) (Bolsista Capes - BEX 4160/13-4).

${ }^{3}$ Ao organizar e publicar Os Cocos, parte da obra em preparo deixada por Mário de Andrade, Oneyda Alvarenga dá explicações sobre o acervo e nos apêndices reúne e apresenta a documentação encontrada relativa aos planos da obra, o início do prefácio (abertura ou introdução), fichas e notas para sua elaboração e esquemas, e todos os registros "destináveis a notas aos cocos" (991 fichas que juntamente com outros documentos, a discípula encontrou numa caixa de papelão, em cuja tampa Mário de Andrade escreveu, a lápis vermelho e em letras grandes, a palavra "Sagrado"), além de um estudo sobre a literatura dos cocos, as crônicas e artigos sobre o cantador Chico Antônio.

${ }^{4}$ Denominação dada provavelmente por Mário de Andrade ao conjunto de textos poético-musicais repassado por Villa-Lobos, cuja pesquisa, em parte, constituiu-se de recolhas feitas pelos Oito Batutas, entre 1919 e 1921, em viagens pelo Brasil patrocinadas por Arnaldo Guinle.

${ }^{5}$ Lembre-se aqui que nos escritos de Mário de Andrade sempre se cruzam poesia e música, fios que unem o artista multifacetado e mediam suas reflexões sobre a cultura brasileira.

${ }^{6}$ Numeração dada por Oneyda Alvarenga na organização das notas para a publicação de Os Cocos. 
7 Bakhtin não faz distinção entre o enunciado e enunciação, ou melhor, emprega do termo viskázivanie quer para o ato de produção do discurso oral, quer para o discurso escrito, o discurso da cultura, um romance já publicado e absorvido por uma cultura. Por essa razão, resolvemos não desdobrar o termo (já que o próprio autor não o fez) e traduzir viskázivanie por enunciado. [N.do T] (BAKTIN, 2010, p.262).

${ }^{8}$ Pesquisas ao Fundo Mário de Andrade do Arquivo IEB/USP realizadas em janeiro e novembro de 2012 para a coleta de dados e desenvolvimento da dissertação cujo capítulo final constitui-se parte do presente trabalho.

${ }^{9}$ Trata-se de entrevista de Villa-Lobos concedida a Alcântara Machado para o Jornal do Comércio em 08/01/1925, no salão do Mappin, referindo-se ao acervo folclórico de poesia e música de Arnaldo Guinle repassado a ele. (MVL-02.042.1a 00).

${ }^{10}$ Doravante FVL.

${ }^{11}$ Dados confirmados tanto pela entrevista de Villa-Lobos ao Jornal do Comércio de São Paulo em 8/01/1925, quanto pela carta de Arnaldo Guinle, identificada pela pesquisa, referindo-se ao assunto em pauta. (ARQUIVO DO MUSEU VILLA-LOBOS/RJ).

${ }^{12}$ A síntese da entrevista e o recorte do Jornal do Comércio: "Villa-Lobos e o Folclore Nacional". datado de 8/1/1925 encontram-se no Arquivo do Museu Villa-Lobos/RJ e foram cotejados com a citação de Ruth Terra.

13 "Canção de Viola" é uma das partituras presentes nos FVL cujo registro de local e data referenda o período da viagem dos Oito Batutas ao Recife.

${ }^{14}$ Somente duas pesquisas se debruçaram sobre esse acervo: $A$ literatura de folhetos nos Fundos Villa-Lobos, da antropóloga Ruth Brito Lêmos Terra, publicada pelo IEB/USP, em 1981, e A outra face dos Fundos Villa-Lobos, de Edilene Matos, estudo de pós-doutoramento ainda não publicado.

\section{REFERÊNCIAS}

ANDRADE, Mário de. Os cocos. Introdução, organização e notas de Oneyda Alvarenga. São Paulo: Livraria Duas Cidades/INL, 1984.

BAKHTIN, Mikhail Mikhailovich. Estética da criação verbal. Prefácio à edição francesa Tzvtan Todorov; Intodução e tradução do russo Paulo Bezerra. 5. ed. São Paulo: WMF Martins Fontes, 2010.

- Problemas da poética de Dostoiévski. Trad. russo, notas e prefácio de Paulo Bezerra. 5. ed. Rio de Janeiro: Forense Universitária, 2010.

ZUMTHOR, Paul. Performance, recepção e leitura. Trad. Jerusa Pires Ferreira e Suely Fenerich. São Paulo: Cosac Naify, 2007. 


\section{Arquivos institucionais}

Arquivos de Mário de Andrade - Instituto de Estudos Brasileiros/USP/SP.

Arquivos de Villa-Lobos - Museu Villa-Lobos/RJ.

Arquivos do MIS - Série Depoimentos. Museu da Imagem e do Som/RJ. 